\title{
Da reificação ao reconhecimento das pesquisas qualitativas em educação ${ }^{1}$
}

\section{From the reification to the acknowledgement of qualitative researches on education}

\author{
Amarildo Luiz Trevisan ${ }^{2}$
}

\begin{abstract}
RESUMO
Há uma transição do discurso sobre a reificação que acompanha, de certo modo, o avanço das pesquisas qualitativas em educação. Do peso excessivo na objetividade do invólucro economicista, baseado na quantificação dos procedimentos, conforme se faz presente na crítica de Lukács, ela transitou para o acento na captação da qualidade subjetiva ou na singularidade dos indivíduos, como demonstra a análise de Adorno da obra de Kafka. Contemporaneamente, a reificação, com a apropriação de Axel Honneth, passa a ser vista no panorama da intersubjetividade. Nesse caso, ela acaba sendo conceituada como ausência ou esquecimento do reconhecimento do outro. É nesse contexto que podemos nos perguntar, neste artigo, sobre o que pode ser pensado como equivalente à negação ou esquecimento do reconhecimento nas pesquisas qualitativas em educação? Como poderemos, então, lutar por novos padrões de reconhecimento das pesquisas qualitativas, estando assim mais implicados com esses conteúdos?
\end{abstract}

Palavras-chave: reificação; intersubjetividade; reconhecimento do outro; pesquisas qualitativas; educação.

\begin{abstract}
There is a speech transition about reification that follows, in a certain way, the progress of qualitative research on education. From the excessive weight
\end{abstract}

DOI: $10.1590 / 0104-4060.32200$

1 Artigo resultante do desenvolvimento do projeto de pesquisa "Teoria e prática da formação no reconhecimento do outro", financiado com bolsa Produtividade em Pesquisa, do CNPq.

2 Universidade Federal de Santa Maria. Centro de Educação. Santa Maria, Rio Grande do Sul, Brasil. Av. Roraima, nº 1.000 - Prédio 16 - Campus Camobi. CEP: 97105-900. 
on the objectivity of the economical involucre, based on the quantification of the procedures, as in Lukács critique, it has moved to emphasize the capture of the subjective quality or the singularity of the individuals, as the Adorno analysis of Kafka's work demonstrates. Contemporaneously, reification, with the appropriation by Axel Honneth, starts to be seen in the intersubjective view. In that case, it ends up being conceptualized as absence or forgetfulness of the acknowledgement of the other. It is on that context that we can ask ourselves, in this article, about what could be thought as equivalent to denial or forgetfulness of the acknowledgement on qualitative researches on education? How could we, then, fight for new patterns of acknowledgement of qualitative research, being, in that sense, more implicated with those issues?

Keywords: reification; intersubjectivity; acknowledgement of the other; qualitative research; education.

\section{Considerações iniciais}

A polarização, com a pretensa objetividade oriunda das ditas ciências duras, levou as ciências humanas a adotar a "perspectiva participante" em suas pesquisas, como forma de romper com esse legado. No entanto, o que se observa hoje no interior do universo das pesquisas qualitativas é a adoção de certo perspectivismo, que acaba contribuindo para criar um novo absoluto, agora não mais sob o império da objetividade, mas da subjetividade. Fazendo valer uma literatura surgida no início da década de 90 do século passado, Zaia Brandão (2002, p. 86-87) já alertava para os riscos que corria a pesquisa educacional ao dizer:

Estamos cada vez mais afastados das ortodoxias teórico-metodológicas, mas perigosamente próximos de um vale-tudo científico, cujos alertas já nos vêm sendo dados em diversos momentos por vários autores, como por exemplo: o risco da "História em Migalhas" (Dosse, 1994), a proposta de relativização do relativismo no âmbito da antropologia (Velho, 1991), a crítica às "superinterpretações" dos textos (Eco, 1993), e a atenção ao rigor necessário à pesquisa com histórias de vida, em virtude do risco da "ilusão biográfica" (Bordieu, 1994).

Nesse contexto, as pesquisas ficaram por vezes à mercê dos sabores da moda, dos gostos e dos habitus próprios de cada perspectiva teórica, sem 
condições, portanto, de dialogar com a perspectiva do outro, o que demonstra um comportamento reificado. Por isso, este artigo pretende abordar a crise das pesquisas qualitativas em educação, mostrando que a tendência à reificação, presente tanto na instância da objetividade quanto na da subjetividade, não garante um avanço ao seu processo, muito menos garante juntar o quantitativo ao qualitativo, o que seria apenas uma forma de harmonizar o problema sem encontrar-lhe uma solução. Pretendemos defender a ideia de que a virada do reconhecimento na Teoria Crítica favorece compreender a inércia de certas abordagens das pesquisas qualitativas. Propomos desvendar o "reconhecimento prévio do outro" como uma condição não epistêmica fundamental das pesquisas qualitativas, evitando assim certos problemas ocasionados pela reificação, isto é, a atitude de não reconhecer o saber emergente das diferenças, produzindo um conhecimento não instrumentalizado e nem coisificado. Mas para isso é preciso equacionar a discussão em dois sentidos básicos: o primeiro, relativo à historicidade das pesquisas qualitativas; o segundo, concernente à busca de resposta à crise das investigações qualitativas, ao propor a mudança de sua base de justificação. Pensada a partir da perspectiva da reificação ao reconhecimento, conforme propõe Theodor Adorno e, principalmente, Axel Honneth, cremos que tais pesquisas não perderão de vista a capacidade de implicar-se positivamente com o outro e, desse modo, não serão mais governadas por narrativas simplesmente lineares, descritivas e de negação do reconhecimento original.

\section{A reificação nas pesquisas qualitativas em educação}

As pesquisas qualitativas surgem como alternativa ao modo de pensar objetivante oriundo das denominadas "ciências duras". Com isso, elas buscaram resguardar o lugar ocupado pela lógica da pesquisa de corte empírico/positivista de forma absolutizada, já que suas atividades se restringiam, em grande medida, à produção de resultados mensuráveis ou comprovados estatisticamente. A alternativa aos métodos positivistas se instituiu primeiramente pela contribuição da fenomenologia, que procurou resguardar a unicidade da experiência e, portanto, a irredutibilidade do acontecer humano a fórmulas preconcebidas e abalizadas pela pesquisa empírica. Aos poucos, essa postura foi se consolidando na adoção do paradigma subjetivista/construtivista/interpretativo, com a necessidade de "ir a campo" para adotar "a perspectiva participante", pois tal atitude se tornou sinônimo de compromisso ou de engajamento social. Zaia Brandão mapeou a emergência desse fenômeno no final do século passado da seguinte maneira: 
Com a chegada da década de 80 , portanto, a crítica ao positivismo e ao caráter demasiadamente genérico das enquetes estatísticas (surveys) distantes dos problemas das escolas e das salas de aula - acabou por provocar uma virada hegemônica no campo das estratégias metodológicas na sociologia da educação. Os estudos de caso, a observação participante e as estratégias de pesquisa qualitativa foram gradativamente dominando a pesquisa em educação. Esta mudança se deu com tal ênfase nessas duas últimas décadas que, em determinados fóruns, a presença de estatísticas educacionais passou a ser associada, com boa dose de preconceitos, aos 'aparelhos do Estado' (BRANDÃO, 2002, p. 105).

Buscou-se assim diminuir a distância entre a produção da teoria e a sua prática, bem como conferir ou devolver a voz para as maiorias silenciadas pela opressão dominante. Esse avanço é inegável, na medida em que passamos a perceber o fator humano como condição imprescindível para a ocorrência do conhecimento. "Entretanto", como apresenta o diagnóstico de Alves-Mazzotti:

apesar da aparente valorização da teoria, o que temos visto é que muitas pesquisas, sob a alegação de "dar voz" aos sujeitos ou de valorizar as práticas, limitam-se a reproduzir falas e falas dos sujeitos, sem qualquer tentativa de identificar regularidades, relações e categorias e/ou se servir de um instrumental analítico capaz de organizar e dar sentido aos dados (2001, p. 43).

Com base nessas avaliações, torna-se perceptível que a herança da discussão petrificada na objetividade levou à adoção da perspectiva contrária, isto é, a defesa, por vezes, de forma enfática da subjetividade como instância fundamental de apropriação de toda e qualquer realidade por parte das investigações. Além disso, passadas algumas décadas de experiências com as pesquisas qualitativas, temos alguns problemas de diálogo entre as mesmas, em função da pluralidade de perspectivas que se colocam sobre qualquer tema ou problema, bem como certo fechamento do universo de interlocução somente entre os "iniciados". Desse modo, as pesquisas ficaram presas aos ditames das modas ou gostos e habitus próprios de cada perspectiva teórica, sem condições de diálogo efetivo com outras configurações, impossibilitando o necessário compartilhamento de saberes. Ainda de acordo com a avaliação de Alves-Mazzotti a esse respeito: "O fato de que esses estudos costumam ser restritos a uma situação muito específica e de que a teorização se encontra ausente ou é insuficiente para que 
possa ser aplicada ao estudo de situações semelhantes resulta na pulverização e na irrelevância desses estudos" (2001, p. 41).

Logo, o que parecia ser uma solução para afirmar as pesquisas qualitativas frente ao pensar objetivante - e é a essa solução que chamamos de perspectivismo teórico -, acabou virando o "feitiço contra o próprio feiticeiro". Afinal: "Fechar-se em um paradigma significa uma incapacidade de compreender e traduzir corretamente o discurso do adversário, impedindo, dessa forma, o tão necessário debate de ideias e de teorias" (DE BRITO; LEONARDOS, 2001, p. 12). E isso significa reafirmar também que o esforço de deslocar o debate, que ocorria, predominantemente, no polo da objetividade, levou-as a um fechamento epistêmico no polo do sujeito.

É por isso que as próprias pesquisas qualitativas também se deparam atualmente com a presença da reificação: "A crescente valorização da prática e da subjetividade parece estar levando a uma tendência à reificação da prática e do sujeito, em prejuízo da construção de conhecimentos relevantes e do diálogo com os autores que já se ocuparam do tema" (ALVES-MAZZOTTI, 2001, p. 43). De acordo com o que dissemos anteriormente, a dificuldade creditada pela vigência e proliferação de certo perspectivismo teórico ou subjetivismo acabou reduzindo a fiabilidade de tais pesquisas, diminuindo o seu raio de alcance e de interlocução com outras perspectivas. E isso redundou no que Alves-Mazzotti denomina "pobreza teórico-metodológica na abordagem dos temas" (2001, p. 40).

No entanto, o desenvolvimento fora do paradigma hegemônico talvez tenha ocasionado nessas pesquisas o que De Britos e Leonardos chamam de "sofrimento por sua precocidade", devido ao fato de "que os próprios critérios de qualidade ainda não haviam atingido o grau de amadurecimento e consenso necessário e corriam o risco de deixar-se contaminar pelos já utilizados no paradigma anteriormente dominante" (2001, p. 11). Zaia Brandão é conclusiva a esse respeito, quando emite o diagnóstico de que "a proliferação dessas abordagens vem indicando que o 'novo movimento teórico' de articulação entre as perspectivas macro e micro, a que se referiu Alexander (1987), não encontrou muitos adeptos entre nós" (2002, p. 105).

É evidente que surgem alguns problemas decorrentes dessas constatações. $\mathrm{Na}$ linguagem adotada por Axel Honneth (2007), poderíamos dizer que tal postura de endurecimento ou fixação na dimensão epistemológica do problema somente demonstra que houve uma perda do que foi aprendido no seu acontecer, sendo esse um indício de que as pesquisas qualitativas estão sofrendo os mesmos efeitos da reificação. A concentração, ou atenção seletiva direcionada apenas à questão do conhecimento, fez com que elas restringissem o seu foco, esquecendo o reconhecimento da dimensão ontológica do problema. 
A percepção e desconfiança de Zaia Brandão em relação ao uso de questionários, por exemplo, pode ser entendida nessa mesma direção:

Para a pesquisa das relações entre famílias e escolas, na perspectiva da constituição e transformação dos habitus, pode parecer que os questionários são limitadíssimos como instrumentos de identificação das práticas sociais subjacentes à constituição das disposições culturais, éticas, escolares, etc. (2002, p. 34).

Sendo assim, os mecanismos de apropriação do saber ficaram bloqueados no campo epistemológico de compreensão, perdendo-se o livre fluxo dos dados entre elementos opinativos, epistemológicos e ontológicos. Há um empobrecimento do debate, porque foi esquecido o contato com as fontes originárias do pensamento, de onde tudo brota e para onde deveria retornar, bem como com a densidade das ideias produzidas em contato com as grandes matrizes teóricas do pensamento.

Não era, porém, objetivo da virada proposta pelas pesquisas qualitativas justamente evitar esse tipo de situação? Por que elas caíram nas malhas da reificação? O que isso significa em termos de sua relação com o desenvolvimento da sociedade?

\section{A reificação na teoria crítica de Adorno}

A educação é um fenômeno social, não apenas algo submisso à escola e, como esta, também está presa às malhas do sistema. É nesse sentido que ela foi compreendida por muitos filósofos ou pensadores ao longo dos séculos, afinal não foram os gregos mesmos a dizer que toda sociedade educa? No entanto, se assim for, e se temos a Grécia como matriz pioneira da cultura ocidental, por que cobramos tanto da escola e dos seus educadores, hoje, em termos de eficiência, produtividade, competência e qualidade, se ainda não vemos absolutamente consolidadas essas reivindicações em sociedades emergentes? Por que, então, a pressão do capitalismo globalizado sobre o desempenho escolar? Por que os educadores estão assumindo esse peso em seus ombros, se isso não é justo ou correto? 
Theodor Adorno auxilia a entender esse fenômeno quando, ao dissertar sobre a obra literária de Kafka, disse: "Como na época da crise do capitalismo, o peso da culpa é tirado da esfera de produção e atribuído a agentes da circulação ou a pessoas que prestam serviços: viajantes, bancários e garçons" (1998, p. 256). E, poderíamos aqui acrescentar, também "ao professor". Essa inversão de responsabilidade não é casuística; pelo contrário ela tem assento num problema que está na origem do próprio sistema capitalista, que Marx chamou de alienação ou reificação. Na verdade, a reificação é a forma mais avançada de alienação, significando, em sua origem, a inversão de causalidade entre os elementos vivos e mortos, ao atribuir qualidades de coisas a pessoas e vice-versa. Adorno ilustra melhor essa situação nesta outra passagem em que analisa a obra de Kafka:

A sua pressão obriga os sujeitos a uma espécie de regressão biológica, preparando o caminho para as parábolas animais de Kafka. Em sua obra, tudo se dirige a um instante crucial, onde os homens tomam consciência de que não são eles mesmos, são coisas (ADORNO, 1998, p. 251).

A reificação é, portanto, para a Teoria Crítica, um tipo de comportamento regressivo, que torna os indivíduos desumanos por assimilar ou mimetizar em sua conduta as formas petrificadas de objetos ou mesmo de animais. Adorno é categórico ao asseverar nesse sentido, a partir de $A$ metamorfose, de Kafka, que "o momento parasitário é deslocado de modo singular. Quem se metamorfoseia em percevejo é Gregor Samsa, e não seu pai” (ADORNO, 1998, p. 252). Logo, os indivíduos assumem essas características mesmo não tendo responsabilidade por isso; ela simplesmente acontece devido ao peso que o sistema exerce sobre todos.

No entanto, para Lukács, o peso da ontologia da objetividade era inerente ao processo de constituição das massas, sendo a reificação considerada uma segunda pele, ou, como ele mesmo defende: uma segunda natureza. Sua dominação é a tal ponto que, conforme o testemunho de Mészáros, para Lukács a consciência dos operários estava reificada (2009, p. 360). Mas, para Adorno, há um deslocamento da obrigação imposta pela objetividade ao plano individual. É igualmente a literatura de Kafka que serve de testemunho para esse pensamento, ao ilustrar: "Prometeu, segundo uma parábola de Kafka, acaba por se identificar com a pedra à qual está preso, sendo então esquecido" (1998, p. 242). Ou seja, o indivíduo, neste caso, Prometeu, adquire as particularidades do meio a que está preso e acaba sendo deformado por elas. Quando comenta o estilo literário utilizado pelo autor, Adorno assim complementa seu pensamento: 
Devido a esta semelhança, Kafka obriga o expressionismo - cujo caráter quimérico ele percebeu como nenhum de seus amigos, mas ao qual ele ainda assim permaneceu fiel - a uma épica tortuosa; a pura subjetividade, necessariamente alienada e transformada em coisa, é levada a uma objetividade que se exprime através da própria alienação. A fronteira entre o humano e o mundo das coisas torna-se tênue (ADORNO, 1998, p. 260).

Ou seja, a pressão da "segunda natureza" sobre a singularidade leva o sujeito a sucumbir diante da reificação imposta pelo sistema, tornando-o incapaz de se engajar numa tarefa coletiva. Mas de que forma a nova fronteira da reificação se deslocou para as particularidades? Adorno mesmo ajuda a entender melhor essa questão, quando diz:

O chamado "problema da contingência", que tanto atormenta os sistemas filosóficos, foi criado por eles mesmos: tudo o que escapa pelas malhas de sua rede torna-se, em razão da própria inexorabilidade do sistema, um inimigo mortal, da mesma maneira como a rainha mítica não encontra paz enquanto existir alguém, para além das montanhas, mais belo do que ela, a criança do conto de fadas (1998, p. 253).

A rainha mítica a que Adorno se refere, presente na história da Branca de Neve, simboliza os imperativos sistêmicos e a sua dificuldade em reconhecer as singularidades, as quais fogem da sua forma de operar. A criança, em tese, representaria a possibilidade de fuga da dominação estética do belo, mas a verdade dita pelo espelho à rainha não a deixa em paz. Um ser frágil é incapaz de articular uma contraposição à dominação "da rainha" e por isso, no desdobramento da narrativa, ela encontra os 7 anões e, mais tarde, o príncipe. Mas Adorno não vê saídas na obra de Kafka para esse problema, a não ser formular uma literatura que demonstra a entrega a esse processo, para, "através da reificação do sujeito, exigida de antemão pelo mundo, sobrepujar, na medida do possível, essa reificação" (1998, p. 269). Ou seja, não há superação possível senão assumir esse fenômeno como forma de protesto, explicitando literariamente a submissão da primeira à segunda natureza, como o próprio Luckács denunciava. "Como há milhares de anos, Kafka procura a salvação pela incorporação da força do inimigo. $\mathrm{O}$ encanto da reificação deve ser quebrado, na medida em que o próprio sujeito se reifica. O sujeito deve executar aquilo de que padece" (1998, p. 268).

É nesse sentido que essa forma de alienação está presente em vários fenômenos da cultura, sendo bem evidente atualmente na estetização do co- 
tidiano - além da literatura, também na publicidade, nos filmes, telenovelas, etc. Justamente por isso ela vem sendo retomada como metodologia de análise do cultural - como propõem Fetherstone (1995) e Frederic Jameson (1995). Oportunamente voltaremos a esse ponto, ao analisar essa categoria como forma auxiliar na leitura dos processos de estetização, através da análise de um filme. Procuraremos exemplificar que a reificação exige uma tomada de posição mais abrangente, isto é, o cultivo de uma preocupação mais ampliada com os destinos do mundo comum. Antes, porém, iremos tratar da presença da reificação nos processos intersubjetivos de compreensão, procurando demonstrar um novo enfoque para tal discussão, conforme assevera Axel Honneth.

\section{A reificação no giro do reconhecimento do outro}

Tanto Hans-Georg Gadamer quanto Jürgen Habermas, mas também autores mais recentes como Axel Honneth e Charles Taylor, assim como já acontecera com os pioneiros da Escola de Frankfurt, entre eles, Theodor Adorno e Walter Benjamin, guardam uma profunda dívida com Hegel. De alguma forma, todos são devedores do diagnóstico da (in)compreensão contemporânea do giro do pensamento do eu ao outro - da esfera da subjetividade para a intersubjetividade - presente embrionariamente no pensamento hegeliano. Não por acaso, a proposta de reconhecimento das diferenças ${ }^{3}$ considera a metáfora do senhor e do escravo, utilizada por Hegel na Fenomenologia do Espírito, como ponto de partida da sua visada propositiva. Visto criticamente, há um componente subversivo na ideia do reconhecimento, porquanto o escravo se submete ao seu senhor, não apenas pelas relações de dominação e servilismo, mas também de estima, consideração e reverência. No sentido positivo, poderíamos pensar na possibilidade de uma relação intersubjetivamente autêntica passar pelo processo de reconhecimento mútuo, porém a sua negação pode ser sintoma de reificação?

A primeira dimensão é importante para a vigência do ideal normativo da hermenêutica, quando está em pauta estabelecer critérios de uma vida boa e digna de realização para todos, por exemplo. Essa alternativa foi incorporada por Axel Honneth, auxiliando na ampliação da virada do reconhecimento na Teoria

3 A teoria do reconhecimento social ou do reconhecimento das diferenças não é simplesmente mais um modismo pedagógico ou da teoria filosófica, pois ela tem raízes na transição do século XVIII para o XIX. Foi concebida por Hegel ao longo de várias obras, porém é na Fenomenologia do espírito que ele irá explicitar mais claramente o sentido de sua tese. Atualmente ela vem sendo recuperada por vários autores, entre eles Axel Honneth, Nancy Fraser e Charles Taylor. 
Crítica (HOLMES, 2009), já iniciada por Jürgen Habermas e Karl-Otto Apel. A consciência dessa mudança de perspectiva, a qual posiciona o "outro" como categoria-chave da compreensão, se faz presente da seguinte maneira no texto Una patologia social de la razón. Sobre o legado intelectual de la Teoría Crítica:

También el concepto de razón con el que la Teoría Crítica intenta captar los incrementos de racionalidad en la historia humana está sujeto a la presión de incluir criterios ajenos y nuevos, no europeos; por eso no sorprende que también el concepto de racionalidad social deba ampliarse y diferenciarse permanentemente para poder dar cuenta del carácter multiforme de los procesos sociales de aprendizaje (HONNETH, 2008, p. 41).

A partir da elevação do "outro", do que foge dos critérios europeus, à categoria central para pensar os procedimentos pedagógicos, muda o tratamento dado inclusive à história do conhecimento, tornando mais sensíveis as experiências de não reconhecimento. Por isso há um acréscimo crítico nessa perspectiva, melhor explorado no seu outro livro intitulado Reificación: un estudio en la teoría del reconocimiento, na medida em que a sua negação, isto é, a reificação, é definida como "esquecimento do reconhecimento".

O reconhecimento prévio do outro é condição para uma relação não alienada e de engajamento, por tomar parte existencialmente da ação ou da práxis, e não apenas participar de sua rotina diária ou do seu convívio.

Se este reconhecimento prévio não se realizar, se não tomamos mais parte existencialmente no outro, então nós o tratamos repentinamente apenas como um objeto inanimado, uma simples coisa; e o maior desafio para a tentativa de reabilitar a categoria da reificação consiste na dificuldade de explicar a condição de possibilidade desta supressão do reconhecimento elementar (HONNETH, 2008, p. 75).

O acolhimento prévio quebra pela base a reificação porque possibilita dar um passo importante na compreensão desse fenômeno no universo da intersubjetividade. Lukács já havia admitido, segundo Honneth, que existem relações não alienadas, solidárias e fraternas, através do conceito de "práxis de implicação". Porém, com o predomínio do capitalismo, essas relações acabaram 
sendo recobertas, como dissemos anteriormente, pela segunda natureza. Disso decorre, como Honneth observa, que "na relação do ser humano com seu mundo, o reconhecer (Anerkennen) sempre antecede o conhecer (Erkennen), de tal modo que por 'reificação' devemos entender uma violação contra essa ordem de precedência" (2008, p. 71).

Honneth consegue apresentar, a partir de Lukács, boas razões para se crer na existência de uma atitude prévia de reconhecimento ou implicação, pelo menos no que diz respeito ao mundo dos fenômenos sociais. Mas ele se depara com uma questão fundamental: "Como puede explicar Lukács el que se llegue a una perdida de esta forma de conducta original, si está supuestamente tan enraizada en la forma de vida del hombre[?]" (HONNETH, 2007, p. 85). Então, se em praticamente todos os processos sociais se impõe alguma forma de objetivação, isso já constitui reificação - nesse sentido, a sociabilidade humana teria se dissolvido. Honneth explica que essas questões são sequelas da estratégia conceitual desenvolvida por Lukács no momento em que equipara a reificação com a objetivação. Daí que, para o desenvolvimento ulterior de suas reflexões, Honneth leva as suas investigações de maneira tangencialmente diferente das de Lukács. Assim defende que, em vez de pensar que o reconhecimento e o ato de conhecer, mediante processos objetificadores, estariam em estados de incompatibilidade constante, ele coloca a argumentação em outros termos. De um ponto de vista mais abrangente, "a las formas sensibles al reconocimiento, por un lado, corresponden, por otro lado, formas del conocimiento en las que se ha perdido la capacidad de percibir su origen en el reconocimiento previo" (2007, p. 91). Perseguindo as intenções de Lukács num outro nível, Honneth explica que:

Podríamos entonces llamar "reificación" a tal forma del "olvido" del reconocimiento"; y con ello nos referimos al proceso por el cual en nuestro saber acerca de otras personas y en el conocimiento de las mismas se pierde la conciencia de en qué medida ambos se deben a la implicación y el reconocimiento previos (HONNETH, 2007, p. 91).

Daí por que o novo conceito-chave de reificação esclarecido por Honneth, ligado à ideia de esquecimento, tem a ver com o fato de que, ao lidarmos com o conhecimento, perdemos a capacidade de perceber e sentir que a sua constituição se deve à adoção de uma "postura de reconhecimento". Por isso acabamos por desenvolver a tendência de perceber as outras pessoas como coisas ou objetos insensíveis. Honneth se pergunta, então, como é possível que o reconhecimento 
prévio seja esquecido tanto geneticamente quanto categorialmente durante nossos envolvimentos diários com operações que envolvem o conhecimento? Ele explica que o esquecimento não tem o sentido usual de subtrair da consciência ou desaprender alguma coisa, antes se trata de uma classe de diminuição da atenção que leva o reconhecimento a ser passado a um segundo plano até que o mesmo se perca de vista.

Sendo assim, a anterioridade do reconhecimento é importante para analisar as pesquisas qualitativas, vez que estas se concentraram muitas vezes simplesmente no conhecimento da realidade, mantendo relações coisificadas com o outro e o seu entorno, ao radicalizar a instância subjetiva. É por isso que o próprio Honneth se apressa em desfazer o equívoco da possível confusão da postura de reconhecimento com a "perspectiva participante", quando afirma:

Também por isso tentei distinguir esta forma do reconhecimento elementar daquilo que na discussão filosófica hoje frequentemente é denominado 'perspectiva participante': a postura que eu tenho em mente antecede a esta perspectiva, pois ela representa a condição não-epistêmica para poder se orientar pelos motivos dos outros (2008, p. 72-73).

A condição não-epistêmica é o fundamento prático da ação, algo pertencente à esfera pré-cognitiva, que oferece suporte para estabelecer um relacionamento que transcende a esfera da reificação, dado que essa já se apoderou da esfera cognitiva pelo seu esquecimento em implicar-se com estes fenômenos. Se pudermos tomar parte existencialmente do universo do outro, supera-se assim a postura de "endurecimento na postura epistemológica", a "atenção seletiva" com caráter neutral, ou seja, o esquecimento do reconhecimento (HONNETH, 2007, p. 96-97).

Por isso, na compreensão contemporânea, a ideia do reconhecimento se tornou um elemento importante para a redefinição crítica de políticas sociais e culturais, passando também a inspirar algumas reviravoltas na compreensão do legado da educação ${ }^{4} \mathrm{e}$, por conseguinte, no universo das pesquisas qualitativas, conforme estamos aqui propondo. Ela é essencial para entender a diminuição do crédito de algumas categorias ligadas ao projeto do Iluminismo ou Esclarecimento (Aufklärung) - como a emancipação ou autonomia, progresso e mesmo

4 Uma das iniciativas pioneiras no campo da educação, no Brasil, é o texto Senhor e escravo: uma metáfora pedagógica, de Hans-Georg Flickinger, publicado no ano de 2000. Recentemente esse artigo veio a lume novamente no seu livro A caminho de uma pedagogia hermenêutica (2010). 
a ideia de consciência, posto que tais categorias estão ligadas à filosofia do sujeito. Nas lutas por essas conquistas houve, muitas vezes, o esquecimento de consultar o outro, se ele queria ou não o tipo de mudança proposto para o avanço social, tanto por projetos ditos progressistas quanto conservadores. Essa base normativa não foi posta em questão quando por vezes se deu voz e vez aos silenciados. Sob o signo da desestabilização do status quo instituído, o reconhecimento implica, portanto, entender a ausência da aceitação, respeito e acolhimento à voz e ao olhar do outro naquilo que está sendo planejado ou idealizado no plano das relações sociais.

Mas a concordância não se restringe ao aspecto cognitivo, atinente à sua posição teórica, ideológica ou epistemológica apenas, o que poderia recair novamente no universo do conhecimento. Antes, porém, essa outra perspectiva vem ao encontro das mudanças nas práticas de convivência que estão ocorrendo nos últimos tempos. Algumas transformações indicam estar em curso uma revolução silenciosa, uma verdadeira mutação dos costumes, dado que a sociedade demonstra estar mais atenta às atitudes de não reconhecimento especialmente nas interações comunicativas. Nesse contexto as políticas sociais e culturais passam por outros filtros de análise, levando em consideração, também, as diferenças de gênero, etnia, cultura, cor, deficiência, etc.

Ao apropriar-se das reflexões sobre o desenvolvimento dos estudos sobre a reificação, podemos perceber, portanto, que há de certa maneira um paralelo com o acontecer das pesquisas qualitativas, que pode servir de espelho para a sua compreensão de forma mais aguda. O desafio por ora é debater o avanço na crítica a posturas reificadas, que não permitem a consideração ao lugar do outro, da alteridade e das diferenças, em plenitude, no universo das pesquisas qualitativas em educação.

\section{Narradores de Javé: reificação ou reconhecimento?}

O embate da problemática discutida no artigo se dá no foco da natureza das metodologias de pesquisa qualitativa e suas respectivas relações com o sujeito/ objeto de investigação, bem como as implicações decorrentes dessas relações com o outro e as formas de produção do conhecimento. Para aprofundar essa abordagem tornou-se necessário discutir uma justificação de base normativa para fugir do problema da reificação apresentada pelo texto. Assim pode ser evitada a crítica de que o reconhecimento estaria preso a um outro tipo de subjetivismo e, portanto, recairia também numa perspectiva epistemológica. 
A crítica de Honneth permite perceber então o quanto as pesquisas qualitativas, ao adotar a perspectiva meramente participativa, oscilaram de um extremo a outro do problema sem lhe oferecer uma solução. Do privilégio dado à objetividade quantitativa, a discussão migrou para o elemento subjetivo, continuando aprisionada às malhas da reificação, pois simplesmente transitou o problema do polo do objeto para o polo epistêmico do sujeito, sem oferecer uma solução para a excessiva fixação em certos procedimentos. A rotinização de certas práticas de pesquisa mediadas pela indiferença e a neutralidade entre as pessoas, bem como o subjetivismo presente na essencialização identitária de certos sujeitos da pesquisa, expresso na abstração de características qualitativas de pessoas humanas, revelam desse modo processos de reificação presentes nessas pesquisas.

A partir da reflexão sobre a "práxis de implicação" de Lukács, é possível perceber que há uma precedência do ontológico sobre o epistemológico e o opinativo, sendo essa uma possibilidade de re-sensibilizar a relação intersubjetiva nas pesquisas. Sendo assim, a postura do reconhecimento não ocorre no nível do conhecimento, e, portanto, no plano epistemológico, mas sim na dimensão ontológica, ou seja, na relação que mantemos com os outros e com o mundo, a qual não se reduz simplesmente à dimensão de conhecimento. No entanto, é uma prioridade que não retira a importância dos outros níveis do conhecimento, mas lhes possibilita uma justificativa prática, mais confiável e legítima. Para explicar melhor o que está pretendendo dizer, Honneth se reporta à categoria do "cuidado" heideggeriano e do "envolvimento" de J. Dewey, dado que a categoria hegelina do reconhecimento demonstra uma função similar. Entra em questão aí outra forma de relacionamento com o real um tanto quanto esquecido nas pesquisas, que é de nível ontológico: um nível ainda mais fundamental porque capaz de produzir a diferença.

Honneth também recorre a Stanley Cavell para trabalhar as relações entre conhecimento e reconhecimento. Honneth defende que ele chegou a uma ideia própria de reconhecimento porque faz uma crítica ao fato de que podemos obter um conhecimento objetivo, categorial e epistêmico dos estados mentais, do chamado psiquismo alheio. Ao contrário, só se pode alcançar compreensão dessas questões como sujeito envolvido existencialmente que toma conhecimento dos estados de sensibilidade de uma forma não neutra, mas afetado por eles numa relação consigo mesmo. Essa atenção terapêutica na comunicação interpessoal, que se faz na intervenção da análise linguística de Cavell, sustenta-se, sobretudo, pela implicação mútua. Portanto, o que está em pauta nessa questão é uma postura semelhante à defendida pelo reconhecimento. Por isso, não temos problemas em entender os pensamentos e sensações de um outro, porque previamente adotamos uma atitude de que os conteúdos de tais pensamentos, enunciados ou sensações nos são dados não de forma estranha, mas natural ou familiar. Desse 
modo, a exegese da reificação empreendida no construto teórico de Honneth reuniu diversas abordagens, ainda que com distintas ênfases, apontando para a mesma direção. Nisso foram incluídos tanto os conceitos de "cuidado" heideggeriano e de "envolvimento" de J. Dewey, quanto as teorias da psicologia do desenvolvimento, como as contribuições teóricas de Cavell, com o objetivo de demonstrar que na conduta social humana existe uma primazia que é ao mesmo tempo genética e categorial do reconhecimento em face do conhecimento, ou seja, de implicação frente à apreensão neutra de fatos ou mesmo da compreensão de outras pessoas. Em suma: "La reificación en el sentido de un 'olvido del reconocimiento' significa entonces, en la ejecución del conocer, perder la atención para el hecho de que este conocimiento se debe a un reconocimiento previo" (HONNETH, 2007, p. 96).

Um exemplo, pela via negativa, pode ser percebido no filme brasileiro Narradores de Javés , que conta a história de um povo que vivia numa pequena cidade do sertão nordestino, ameaçada de ser submersa pela construção de uma usina hidrelétrica. Isso só não iria acontecer, pelas leis vigentes, se a localidade apresentasse um motivo cultural para o seu tombamento, evitando desse modo que a catástrofe viesse a ocorrer. Diante desse desafio, a comunidade se mobiliza e passa - de mera espectadora passiva de sua história e, portanto, presa à inércia da reificação - a atuar conjuntamente com o narrador, Antônio Biá, na escrita da sua história. Ele é o único indivíduo alfabetizado da comunidade que poderia traduzir a oralidade numa "escrita científica". Emergem dessa situação inúmeras histórias hilariantes, e mesmo triunfantes, da origem do povoado, uma vez que todos exigem que a sua versão seja legitimada, desde a valorização de um passado heroico e mítico, até o reconhecimento do papel da mulher e dos pioneiros.

Embora o resultado final não tenha sido dos melhores, uma vez que o narrador era um sujeito inescrupuloso, que acabou não desempenhando o papel que lhe havia sido confiado pela população, importa aqui a colocação do problema pelo filme. Sem dúvida, as estratégias de sobrevivência à coisificação do sistema passam pela mobilização de atitudes coletivas, de engajamento social na produção de um sentido que ofereça garantias de um mundo comum. A participação popular nesse processo torná-lo-ia sujeito do conhecimento produzido, com capacidade de decisão sobre a escrita da trajetória coletiva. Mas isso só não basta, como ficou claro nessa história. Embora participante ativo do processo de construção da narrativa do povoado, em momento algum Antônio Biá de-

5 Produção brasileira de 2003, dirigido por Eliane Caffé, tendo obtido reconhecimento nacional e internacional em vários festivais de cinema, como o prêmio da crítica e o prêmio Gilberto Freyre do Festival do Rio, segundo o júri popular e o oficial, e de melhor filme e melhor roteiro no $3^{\circ}$ Festival Internacional do Filme Independente de Bruxelas. 
monstra sentir-se comprometido ou afetado pelo que está fazendo, até porque ele havia sido excluído da convivência do povoado por problemas ocorridos anteriormente. Pelo contrário, diante das múltiplas possibilidades que se abrem para contar a história do lugar, prefere (talvez exatamente por isso) produzir uma "escrita científica". Como não consegue lidar com a pluralidade de perspectivas exposta pelos entrevistados, acaba por denegar a função realizada. Para isso, seria preciso ir além, não se limitando à iniciativa de "dar vez e voz ao outro", com expectativa puramente "científica", mas antes de tudo far-se-ia necessário o acolhimento em sua singularidade e diferença, o que certamente implica a adesão afetiva ao que está sendo proposto.

\section{Aspectos conclusivos}

Até o presente, falamos que há uma transição do discurso sobre a reificação que acompanha, de certo modo, o desenvolvimento da discussão no campo das pesquisas qualitativas. Do peso excessivo na objetividade do invólucro economicista, baseado na quantificação dos procedimentos, conforme se fazia presente na crítica de Lukács, a reificação transitou para a ênfase na captação da qualidade subjetiva ou na singularidade dos indivíduos, como demonstra a análise de Adorno sobre a obra de Kafka. Contemporaneamente, com a apropriação de Honneth, a reificação passa a ser vista no panorama da intersubjetividade e, nesse caso, ela acaba sendo conceituada como ausência ou esquecimento de reconhecimento do outro. Diante desse novo panorama, podemos enfim nos perguntar: o que pode ser pensado como equivalente à negação do reconhecimento nas pesquisas qualitativas em educação? Como poderemos, então, lutar por novos padrões de reconhecimento das pesquisas qualitativas, estando assim mais implicados com esses conteúdos?

O acento no outro, como fim prático da ação, torna-se um novo modo de compreender tais pesquisas, pois na medida em que há permanência no nível descritivo, epistemológico, ou mesmo, opinativo, não se atinge o cerne da questão. Essa é uma atitude presa à perspectiva do observador ou do mero "participante". O que pode produzir a diferença, nesse caso, é o outro não apenas se fazer presente nos afazeres da pesquisa. Pelo contrário, seu comparecimento alarga o horizonte de compreensão ao ponto de orientar o processo de escolha, mas não somente das opções teóricas e metodológicas, das técnicas e instrumentos ali adotados. Ele sente-se implicado com os próprios fins (normativos) do trabalho a ser desenvolvido. 
O equívoco se dá no acento demasiado na expectativa da apropriação e difusão do conhecimento, bem como no foco do poder ou das necessidades da produção. Por esse caminho, o conhecimento é produzido/pesquisado de modo reificado, isto é, de modo a esquecer as vivências pessoais e coletivas. Agindo assim, seremos pesquisadores autômatos, que não levam em conta os sentimentos e as experiências do outro e que só executam tarefas cognitivas previstas em projetos de pesquisa. No máximo ficaremos somente respondendo em função de apelos exteriores: agências de fomento, avaliações de programas, de projetos ou de pares, etc. Por fim, ficaremos facilmente observando com indiferença ou contemplando, de forma passiva ou mesmo participativa, a sua produção.

O reconhecimento prévio do outro - do elemento vivo, emotivo e cultural - pode quebrar pela base a reificação porque possibilita dar um passo importante na compreensão de tal fenômeno no universo da convivência social. Para isso é importante que não se perca a capacidade de implicar-se positivamente com o dado pesquisado, evitando desse modo ser governado pela atitude de negação do apreço original. Desse modo, quando há consideração prévia do outro, a narrativa se faz valer mais legitimamente. É desse modo que o reconhecimento afetivo subjaz às expectativas puramente cognitivas, frias e neutrais, não existindo construção de autonomia sem que, primeiro, haja acolhimento do ser humano aí envolvido, em suas múltiplas dimensões.

\section{REFERÊNCIAS}

ADORNO, Theodor A. Prismas: crítica cultural e sociedade. São Paulo: Ática, 1998.

ALVES-MAZZOTTI, Alda Judith. Relevância e aplicabilidade da pesquisa em educação. Cadernos de Pesquisa, n. 113, p. 39-50, jul. 2001.

BRANDÃO, Zaia. A dialética micro/macro na sociologia da educação. Cadernos de Pesquisa, n. 113, p. 153-165, jul. 2001.

. Pesquisa em educação: conversas com pós-graduandos. Rio de Janeiro: Ed. PUC-Rio; São Paulo: Loyola, 2002.

DALBOSCO, C. A. Reificação, reconhecimento e educação. Revista Brasileira de Educação, v. 16, n. 46, p. 33-49, 2011.

DE BRITO, Angela Xavier; LEONARDOS, Ana Cristina. A identidade das pesquisas qualitativas: construção de um quadro analítico. Cadernos de Pesquisa, n. 113, p. 7-38, jul. 2001. 
FEATHERSTONE, M. Cultura de consumo e pós-modernismo. Trad. Júlio Assis Simões. São Paulo: Studio Nobel, 1995.

FLICKINGER, H.-G. A caminho de uma pedagogia hermenêutica. Campinas, SP: Ed. Autores Associados, 2010.

HEGEL, G. W. F. Fenomenologia do espírito. Trad. Paulo de Menezes. 5. ed. Petrópolis, RJ: Vozes: Bragança Paulista: Ed. Universitário São Francisco, 2008.

. Princípios da filosofia do direito. Trad. de Orlando Vitorino. 2. ed. São Paulo: Martins Fontes, 1976.

HOLMES, P. Reconhecimento e normatividade: a transformação hermenêutica da teoria crítica. Revista Brasileira de Ciências Sociais, v. 24, n. 69, p. 129-145, 2009.

HONNETH, Axel. Luta por reconhecimento. A gramática moral dos conflitos sociais. Trad. De Luiz Repa. São Paulo: Ed. 34, 2003.

. Reificación: un estudio en la teoría del reconocimiento. Buenos Aires: Katz, 2007.

. Observações sobre a reificação. In: SOBOTTKA, Emil Albert; SAAVEDRA, Giovani Agostini (Orgs.). Civitas Revista de Ciências Sociais, Porto Alegre: EDIPUCRS, v. 8, n. 1, p. 68-79, jan./abr. 2008.

. Sofrimento de indeterminação: uma reatualização da filosofia do direito de Hegel. Trad. Rúrion Soares de Melo. São Paulo: Ed. Singular, Esfera Pública, 2007.

. Uma patologia social da razão: Sobre o legado intelectual da teoria crítica. In: RUSH, Fred. (Org.). Teoria Crítica. Trad. Beatriz Katinsky e Regina André Rebollo. Aparecida, SP: Ideias \& Letras, 2008, p. 389-415.

JAMESON, F. A cultura do dinheiro. Ensaios sobre globalização. Petrópolis: Vozes, 2001. . As marcas do visível. São Paulo: Graal, 1995.

. Pós-modernidade e sociedade de consumo. Novos Estudos. CEBRAP, São Paulo, n. 12, p. 16-26, jun. 1985.

MÉSZÁROS, István. Para além do capital. São Paulo: Boitempo, 2009.

NARRADORES de Javé. Eliane Caffé, Vânia Catani, Brasil/ França: Bananeira Filmes, 2003. 1 filme.

TREVISAN, Amarildo Luiz. Formação ou reificação? A educação entre o mesmo e o outro. Educação \& Sociedade, v. 32, n. 117, p. 1185-1200, 2011.

TREVISAN, Amarildo Luiz; ROSSATTO, Noeli D. Reificação e reconhecimento: reflexões para a pesquisa em educação. Linhas Críticas, Brasília, DF, v. 16, n. 31, p. 275-286, jul./dez. 2010.

Texto recebido em $1^{\circ}$ de junho de 2013. Texto aprovado em 10 de março de 2014. 